\title{
Los concursos o certámenes literarios como actos performativos: El caso del Certamen Varela de 1887
}

\author{
Literary contests as performative acts: Certamen Varela 1887 \\ Darcie Doll y Damaris Landeros \\ Pontificia Universidad Católica de Valparaíso. Chile \\ darciedoll@hotmail.com, damaris.landeros@hotmail.com
}

\section{RESUMEN}

Durante la última mitad del siglo XIX y la primera del siglo XX presenciamos un incipiente proceso de autonomización (relativa) del campo determinado por la profesionalización del oficio escritural y el ingreso de nuevos actores en el campo literario (mujeres y clase media). Uno de los principales medios para dar cuenta de este proceso es el desarrollo de los concursos y certámenes literarios, los que permiten configurar las disputas que se desarrollan en el campo, el canon que prepondera en éste y le dan la oportunidad a los autores de "medirse" con sus pares y con el dispositivo crítico de la época (jurado). En el presente artículo se tomará como ejemplo el Certamen Varela de 1887, dada su importancia en las letras chilenas configurándosele como síntesis de los procesos en desarrollo en el campo literario. Junto a esto, se le instaurará como entidad consagratoria del campo literario todavía dependiente de otros campos producto de su calidad performática en la embrionaria literatura chilena.

Palabras claves: Concursos literarios, actos performativos, Certamen Varela, campo literario, crítica literaria.

\begin{abstract}
During the latter half of the XIX and early XX century we witnessed the incipient process of the (relative) autonomization of the field determined by the professionalization of the craft of writing and the entry of new players in the literary field (middle class and women). One of the main ways to account for this process is the development of literary
\end{abstract}


contests and competitions, which allow us to set the disputes that take place in the field, the canon that preponderate in this and give the opportunity to the authors of "measured" with their peers and with a part of the critical device of the time (the jury). In this article shall be taken as an example the Certamen Varela 1887 because of its importance in the Chilean letters and it's configured as synthesis of the processes developing in the literary field. Along with this, it will be set up as a consecration of the literary field that still dependent because of the performativity quality in the embryonic chilean literature.

Keywords: Literary contests, performative acts, Certamen Varela, literary field, literary criticism.

Recibido: 21-11-2008

Aceptado: 08-01-2009

\section{INTRODUCCIÓN}

- $\mathrm{n}$ Chile, a partir de 1880, finalizada la Guerra del Pacífico, comienza un Croceso de modernización económica, política, administrativa y social, así como una mayor inserción en la expansión mundial del mercado. El analfabetismo comienza a decrecer, aumenta la cobertura en educación, así como la emigración de la población a las grandes ciudades. Se trata de un cambio de escenario (Subercaseaux, 2000) que devendrá en una diversificación del mercado cultural que, aunque no es una ruptura, generará condiciones para transformaciones importantes (Catalán, 1985: 131).

En este contexto se desarrollará el proceso que llevará a la autonomización o conformación del campo literario y a la profesionalización del estamento de los escritores (según una de las propuestas más concretas respecto del campo literario chileno, formulada por G. Catalán a partir de las concepciones de Pierre Bourdieu).

La autonomización (relativa) del campo literario es favorecida por una serie de factores, en primer lugar la emergencia de un grupo de escritores provenientes de las capas medias, a diferencia de la mayoría de los intelectuales de los períodos precedentes. En este marco se produce una ruptura de la fusión entre lo político y lo literario y se inicia la consolidación de un estamento de intelectuales que asumen como función propia y específica la producción de literatura, formado especialmente por escritores ajenos a la clase dominante. En síntesis, se produce un cambio en el espacio cultural configurado en el sistema oligárquico, lo que provocará un proceso de recomposición hegemónica. Esta modernización decantará en nuevas formas de apreciación del hecho literario. 
Si bien los modos anteriores no desaparecen totalmente, la fisonomía del campo ahora se configurará a través de "asuntos de poder interno" al espacio propiamente literario: grupos literariamente hegemónicos versus contendientes o aspirantes (Catalán, 1985).

Los factores que inciden y forman parte de este proceso tienen que ver con el aumento de los medios de masas y la prensa, durante la década de los 90' (Subercaseaux, 2000) y en la que participan los escritores. Asimismo, los escritores comienzan a recibir pago en dinero por su producción, lo que señala un elemento importante en la profesionalización del estamento literario. A esta red se agregan las actividades semiinstitucionales e institucionales, tertulias literarias, ateneos, asociaciones de escritores, etc.

En el proceso brevemente señalado se ubica el espacio de los concursos, que tendrá una importante función como parte de los mecanismos de configuración del campo literario y del campo crítico. Según el estudio de Gonzalo Catalán, los concursos funcionan como mecanismo de selección y promoción de los jóvenes valores literarios, "sirviendo como vía de acceso privilegiado al mundo de las letras":

Dotados de premios en dinero, en modo alguno despreciables, la función más importante de los concursos era la de posibilitar a los escritores, midiéndose con sus pares, acrecentar su 'valor' y 'cotización literaria', que en esas condiciones ya no dependía ni de la posición social ni de la influencia política del escritor sino de sus propios méritos narrativos o poéticos, signo evidente de que el campo literario había sido capaz de generar su propio 'capital' específico y las prácticas correspondientes de acumulación y beneficio (131).

\section{LOS CONCURSOS}

Desde la perspectiva de la performatividad como acto o "performance", que consiste en "actividades humanas" -sucesos, conductas- "que tienen la cualidad de ser una 'conducta restaurada', o 'conducta practicada dos veces'; se trata de actividades que no se realizan por primera vez sino por segunda vez y ad infinitum". Es decir, es un "proceso de repetición, de construcción (ausencia de 'originalidad' o 'espontaneidad')" (Schechner, 2000: 13). Los concursos, en este sentido, son un acto que se realiza con cierta regularidad, una especie de ritualidad consagratoria. El concurso, más allá de su materia, convocantes, modalidad, etc., es una actividad que se repite, pero, y al mismo tiempo, es único, en cuanto a que cada concurso es diferente de otro. Para instituirse en una práctica reconocible debe ser seriada, ejecutarse repetidamente para instituirse como tal. 
Otro aspecto importante de la performance, es que instala identidades:

La performance marca identidades, tuercen y rehacen el tiempo, adornan y remodelan el cuerpo, cuentan historias, permiten que la gente juegue con conductas repetidas, que se entrene y ensaye, presente y re-presente esas conductas. (...) todo género de performance y toda instancia particular de un género es concreta, específica y diferente de todas las demás. Es paradoja fundamental de la performance que cada instancia sea diferente de las otras, mientras que teóricamente la idea misma de performance se basa en la repetición y la restauración. Pero ninguna repetición es exactamente lo que copia; los sistemas están en flujo constante (Schechner, 2000: 13).

Pueden estar orientadas ellas a constituir ruptura temporal o una continuidad restaurada, en ese sentido, los concursos permiten que los participantes se hagan parte de una comunidad determinada, debido al papel consagratorio que éstos juegan en su ámbito específico, y, por otra parte, marcan un cambio, o una diferencia o novedad, pero siempre al interior del modelo, ámbito, comunidad o campo.

El componente reflexivo remite a la puesta en "acción" de los significados, valores y objetivos centrales de una cultura o ámbito, mientras, y a la vez, explican, o instalan culturalmente dicha acción ${ }^{1}$.

Las performances se consideran acontecimientos sociales que obligadamente forman parte de una actividad comunitaria, los actores involucrados en la performance son miembros (o aspiran a serlo) de una comunidad. La comunidad, en nuestro caso es la "comunidad letrada" y está dirigida a los miembros de su comunidad.

Los concursos literarios, entonces, como figura, y en cuanto a una práctica o acto repetido y a la vez único, que pone en acción el sistema consagratorio de actores que forman parte del campo, o, lo desean, funciona como un ritual destinado a legitimar un autor y una obra (un discurso), y puede observarse como acto performativo.

Otra aproximación a lo performativo remite a los enunciados o a los actos de habla, según la tradición de las teorías pragmáticas del lenguaje y sus derivados. Siguiendo el razonamiento de Austin, en Hacer cosas con las palabras (1996), los enunciados pueden ser constatativos o realizativos (performativos). Mientras que los primeros dicen cosas del mundo, los segundos realizan acciones en el mundo a través del lenguaje. Estos serían los llamados actos de habla.

${ }^{1}$ Turner, V. citado por Schechner (2000: 17). 
Pero, posteriormente, el mismo Austin reformula su propuesta afirmando que el poder realizativo que tienen los enunciados es amplio, pues cuando se habla sobre el mundo, se afecta el mismo. Se habla por una razón y para provocar algo. Lo que daría como resultado que todos los enunciados serían realizativos ${ }^{2}$. En el ámbito ilocucionario nos encontraríamos con el centro del acto de habla. Acá tendríamos el contenido de dicho enunciado y en este punto se realizaría lo que Hugo Aguilar en su artículo "La performatividad o la técnica de la construcción de la identidad” (2004) señala como instauración. Instaurar, para Aguilar, es la realización de enunciados en un entorno pragmático creando una entidad inexistente hasta el momento de la emisión. Pero lo cierto es que si dicho enunciado no tiene respuesta, no se puede hablar de un acto de habla en su plenitud. No fue exitoso, o incluso, se podría decir que nunca existió dicho acto.

A pesar de lo señalado anteriormente, no todos los enunciados instauran, aunque sean actos de habla, pues no todos los sujetos que emiten enunciados tienen la posibilidad, conferida por el contexto, de instaurar discursos en la producción de los enunciados. Las relaciones de poder que existen en los contextos interfieren directamente con el poder instaurador de los enunciados.

Por lo tanto, Aguilar concluye que el lenguaje, por sí solo, carece de poder (toda expresión posee una dimensión performativa) pero adquiere poder y adquiere capacidad performativa a partir del carácter institucional del enunciador.

La sustitución de un hacer por el decir no será practicable si no existe, además, alguna garantía de que la enunciación será también seguida de un efecto.

Esta garantía no se encuentra en la lengua, sino en las instituciones. Por institución, entiendo la existencia de un poder normativo que someta mutuamente a los individuos a determinadas prácticas bajo pena de sanciones (Barrendonner, citado en Aguilar, 2004: 4).

Lo institucional es lo que asegura el valor de verdad de las proposiciones y otorga poder al enunciador. "La restitución de una acción por las palabras no depende del poder de las palabras sino del poder de la institución que las avala, es decir, depende de las condiciones de la enunciación”, señala Barrendonner (en Aguilar, 2004: 4).

${ }^{2}$ Para el desarrollo de los actos de habla existen 3 etapas: Acto locutivo: la emisión real del enunciado (¿quieres salir un momento?); Acto ilocutivo: el sentido real de dicho enunciado (sale); Acto perlocutivo: la acción que se logra con la emisión y sentido de dicho enunciado (que la persona a la que va dirigida el enunciado se retire). 
Siguiendo el razonamiento anterior, la performatividad puede entenderse como un proceso de legitimación. J. F. Lyotard afirma que dicho proceso genera una forma de legitimidad que es "puramente instaurativa", porque se construye desde lo "puramente discursivo institucional". Podríamos señalar que de esta forma funcionaría el proceso de construcción de la literatura como institución.

Por otra parte, performativo remite también a ejecución, desempeño (performance), en este sentido, la performance, en tanto actividad colectiva, social o individual es una "forma de la imposición/instauración de una condición particular" (Aguilar, 2004: 5) y que es asumida como configuradora de dicha condición. Es una forma de "legitimación, afirmación y construcción de la identidad. Y como tal, un instrumento al servicio de un grupo de personas de una sociedad que asumen su condición precisamente desde esta performatividad" (Aguilar, 2004: 5).

Ahora bien, si nos estamos refiriendo especialmente al campo del poder/ saber, debemos destacar que en toda interacción la negociación que se establece es no sólo semántica, sino "una disputa de roles sociales y de poder pragmático, o lo que es lo mismo: es una disputa sobre nuestro derecho a influir o de ser influidos por el otro" (Aguilar, 2004: 7).

Los concursos, literarios, poseen las cualidades antes señaladas, funcionan como actos rituales destinados a instaurar, configurar, ejecutar un acto colectivo, que "adquiere capacidad performativa a partir del carácter institucional del enunciador”, proceso que se establece al interior de la negociación en el campo simbólico, instaurando roles y actores, legitimando, afirmando y construyendo identidades literarias.

Los concursos activan la "competitividad", que "es el mejor índice para medir el grado de autonomía que ha alcanzado el campo". Menciona Catalán:

[...] sobre la base de un esquema concurrencial, donde cada cual busca maximizar sus beneficios literarios/económicos, se generan muchos de los fenómenos que hacia esos años conoce la literatura chilena: las afinidades y oposiciones entre escritores y escuelas, sus reconocimientos y distanciamientos, sus definiciones y pronunciamientos, estarán determinados en gran medida por la preocupación de ganar y controlar posiciones en un mercado que desde ahora se visualiza por sí mismo como gratificante (1985: 132).

En ese marco, el concurso, Certamen Varela, funciona, por sus especiales características, como un modelo de los concursos literarios, y es un acto y discurso paradigmático en cuanto en él cristalizan elementos que están concurriendo aisladamente en la formación del campo literario chileno, pero 
que con este acto "instauran una síntesis" o una puesta en acción de estos elementos en conjunto. Algunos de los elementos que conforman esta síntesis del certamen como acto performativo:

1. Instaura la existencia del campo literario chileno y es un evento (acto) que marca también el "espacio-crítico literario chileno, en cuanto a un acto que sintetiza los componentes que forman un campo.

2. Instaura la existencia de grupos al interior del campo: incumbentes y contendientes, grupos que responden a lo específicamente "literario" y ya desgajado del anterior campo social/cultural que reunía en la intelectualidad papeles y funciones diversas, incluyendo las políticas. Es un acto que pone en escena la lucha por el poder simbólico.

3. Legitima "desde lo discursivo institucional" a los agentes del campo. Los actores o agentes: concursantes, jurado, críticos, son legitimados como miembros de la comunidad o institución literaria, siendo el concurso producido por los mismos actores. El concurso instaura a los concursantes. Participar es ser. Ganar es doblemente ser.

4. Instaura una institución con identidad. La institución "literatura nacional"3, en cuanto la institución en formación es el sujeto del acto, y se evalúa exitosamente su existencia, demostrada en el concurso, frente a los discursos de la carencia de literatura nacional que abarcan las décadas anteriores del siglo XIX. (La instala y consagra con una cuota significativa de legitimidad, más allá de la existencia de los hechos literarios).

5. Exhibe el circuito completo, que incluye las consecuencias del acto: polémicas, crítica periodística, publicación de los textos, etc.

6. El sujeto y objeto del acto es el mismo: la comunidad literaria, o institución literaria o campo literario en plena autonomización. (La institución sanciona la existencia de la institución, implícitamente).

7. Instala el campo con la legalidad del mercado simbólico: publicación y difusión, premio en dinero a los concursantes (profesionalización del escritor), competencia entre sujetos.

8. Está configurado con la ritualidad consagratoria al ejecutarse: además de lo anterior, como evento, que tiene entre sus componentes la fiesta de premiación final.

${ }^{3}$ Una pequeña nota: Es de común acuerdo que el discurso de Lastarria de 1842 es un texto que funda la literatura nacional, en acuerdo con ello, debemos decir que el carácter fundacional de un texto, sólo es a posteriori. Lo que falta es la recepción inmediata, recepción crítica, recepción pública, y que se mantenga una continuidad más que una pausa. Si se desea profundizar en la importancia de dicho discurso, ver Promis (1977). 
Todo lo anterior, entonces, es avalado desde la instancia de poder que significa la institución enunciadora, que se está haciendo de las leyes, normas, y componentes, construyéndo/se como legalidad: la autonomía relativa del campo literario.

Ahora bien, entendemos el concurso como una instancia compleja, incluye: 1. La planeación: 2. la convocatoria y recepción de los trabajos; 3. el veredicto del jurado; 4. la publicación del veredicto (informe), y 5 . los efectos o respuestas de la comunidad (recepción de la crítica, de los escritores, del público, polémicas).

Por razones de tiempo, nos referiremos a algunos de ellos para ilustrar los aspectos mencionados antes:

\section{La planeación}

El Certamen Varela fue convocado en 1887, a instancias de Federico Varela ${ }^{4}$, empresario minero aficionado a las letras, quien aportará los premios en dinero. Varela acude a Lastarria para que lo organice. Las razones para lanzar la convocatoria se enmarcan en el discurso que señala que se está en un proceso de "estancamiento de las letras nacionales", según José Victorino Lastarria. Se trata del programa que proviene del discurso y proceso enmarcado en el año 1842.

Varela señala:

Desde luego, se advierte cierto desmayo en el cultivo de las letras, i si los certámenes no dan todo su fruto, es porque a ellos concurren los principiantes casi esclusivamente.

¿Falta acaso el talento poético en el país? ¿Hay desdén por el cultivo de las letras? Por el contrario, yo creo que entre nosotros hay muchos ingenios aún anónimos, como las piedras rodadas del desierto, a las cuales el viajero da con el pie, sin sospechar que en sus entrañas ocultan el oro y acaso el diamante (1887: 1).

Los fundamentos del llamado, mediante la carta citada, dan cuenta del problema central, "descubrir el talento poético" oculto. En el contexto de una carencia en las letras chilenas que Varela destaca debido al escaso éxito de un

${ }^{4}$ La incursión de Federico Varela, empresario minero aficionado a las letras, recuerda algo la institución del mecenazgo antiguo, que en Chile no tiene gran significación, pues no es asociable a las capas que detentaban el poder simbólico durante el siglo XIX, pues no delegaban en otros estratos el poder simbólico a través del poder económico, sino que ellos mismos lo ejercían. Estamos hablando de las elites ilustradas de Chile. En su interior, sean conservadores o liberales, es donde se produce capital simbólico, en términos de Bourdieu. Por lo tanto, podríamos decir que Varela representa más bien un desplazamiento del lado del mercado moderno, un elemento que no corresponde al intelectual ilustrado, ni a la academia. 
intento anterior, el certamen de 1886, que no tuvo aceptación sino críticas negativas por la falta de calidad de los concursantes (llamados "principiantes").

J. V. Lastarria acepta la invitación y se forma una comisión conformada también por Diego Barros Arana y Manuel Blanco Cuartín.

\section{La convocatoria y recepción de los trabajos}

El centro neurálgico de la convocatoria es un objetivo patriótico, apoyar a la literatura nacional.

Felicitamos muy sinceramente al señor Varela. El glorioso día del 21 de mayo no podía ser mejor rememorado ni festejado, ni los mártires del combate de Iquique pueden recibir mejor ofrenda de admiración que el estimulo y el empuje que dé al cultivo de las letras en un país en que, como el nuestro, la literatura nacional recién se abre camino (Varela, 1887: 3).

La convocatoria de este certamen, que difería del anterior en su amplitud (tanto en temáticas como representatividad), difiere también en que ya no se deseaba buscar nuevos escritores, sino los escritores fundamentales de la literatura chilena. Este cambio marcará la presencia de grupos que no se visibilizan anteriormente, tensionando la constelación de los campos de producción simbólica.

Los temas seleccionados fueron seis:

1. Canto épico a las glorias de Chile en la Guerra del Pacífico.

2. Poesías líricas inéditas.

3. Tratados didácticos del español.

4. Estudio político-social referente a Chile.

5. Estudio de las costumbres nacionales.

6. Colección de fábulas en verso.

Esta amplitud da cuenta de una novedad y cristaliza también un proyecto instaurador al intentar abarcar todo el espectro de los géneros más prestigiosos y siguiendo los principios que Lastarria y su grupo han intentado instalar desde la década del 40.

Asimismo, se instala el problema de la carencia especialmente en algunos temas; en el tema 5 (estudio de las costumbres nacionales) y en el tema 6, correspondiente a las fábulas en verso. Respecto de éste se señala: "Este jénero 
merece a mi juicio, ser cultivado, y por tanto, ya que entre nosotros es escaso, conviene estimularlo" (Varela, 1887: 5).

Otro aspecto importante es la inclusión en la convocatoria de la modalidad del concurso como evento, además de las fechas y modalidad de entrega de los fallos, se menciona que "la junta organizará una fiesta especial destinada a que los autores premiados lean sus composiciones, o parte de ellas, si fuesen mui extensas" y luego, la publicación de un libro que contenga las composiciones presentadas, los informes del jurado "i demás pruebas conducentes a dar una idea cabal del acto literario de que tiene a bien cargarse" (Varela, 1887: 5). Además, se publica el valor del premio en dinero para cada tema.

Finalmente, en un apartado que el jurado señala con fecha 29 de mayo de 1887 se mencionan las formas de presentación de los textos. Primero, ellos deben remitir a cualquiera de los temas las creaciones antes del 1 de agosto de 1887. Y segundo, las obras deben ser acompañadas de un sobre escrito cerrado y sellado, en el que esté el nombre del autor y que esté visible el título de la obra y la contraseña que en ésta se ponga. Esta contraseña luego sería publicada en el diario La Libertad Electoral, pero lo cierto es que como se señalaba anteriormente, los ganadores serían develados en la fiesta, punto de mayor visibilidad del autor. Se lo instaura públicamente, a través de la institución pero en presencia del público.

\section{La publicación del veredicto (informe)}

El veredicto del jurado constituye, a posteriori, quizás uno de los más importantes documentos que muestra los criterios de la institución letrada a fines del siglo XIX. Explica detalladamente los valores y defectos de cada uno de los textos presentados al concurso y constituye una síntesis de los principios que evalúan la producción letrada.

Se trata del discurso de la crítica destinado a juzgar y evaluar los textos. Esta crítica consiste básicamente en una discriminación de las obras auténticamente "grandes" o "principales", con la consecuente categorización de obras "menores" y una exclusión efectiva de las obras "malas" o "insignificantes", a la vez que una comunicación y una realización prácticas de los "principales valores" (Williams, 1980: 65-66).

El informe representa a la tradición de la apreciación crítica antes de consolidarse como discurso crítico-literario en un sentido más moderno, pues es descriptiva y académica rigiéndose por el apego a normas establecidas, no obstante, la pone en acción, y corresponde a la tradición heredada de los estudios del siglo XIX. 
Podemos ver representado esto respecto al tema 2, el de poesías líricas, el informe comienza presentando el tema señalando que las rimas debían apegarse a las de Bécquer por ser del "jenero sugestivo, breve y delicado por esencia, pues sólo insinúa las cosas, i sustancioso porque suele contener mas ideas que palabras, cuadra bien al espíritu de nuestros tiempos i por lo mismo es hoy estimado i conviene que lo fomentemos" (Varela, 1887: 12) y luego se explaya sobre los "tres tipos diferentes" que tiene la poesía española "en nuestros tiempos". Estos serán los criterios para determinar a los ganadores. En este punto se justifica la elección de Bécquer como modelo por su "estilo profundo, i por consiguiente conciso" (Varela, 1887: 13).

Luego de aquello se analizan los versos de cada una de las 45 rimas, determinando las que merecen ser llamadas "las mejores". Cabe destacar lo que los jueces señalan en torno al texto Rimas, poesías líricas del jénero sugestivo de Eduardo de la Barra (utilizando el seudónimo Job), ganador de este tema:

Hai cuarenta i cuatro composiciones que son bellas i bien versificadas. Siendo, como son, fieles a su contraseña Eros, lumen, numen, corresponden al segundo tema del programa. Prescindiendo que en algunas de ellas se encuentra alterada la construcción de sus estrofas, colocando, por ejemplo, un heptasílabo en un lugar distinto del que tiene en las otras, esta licencia parece escusada por la correccion irreprochable de los versos i del lenguaje, i por la inspiración i buena disposición que en todas se notan. Hai algunas limitaciones de Bécquer que tienen novedad, i la que lleva el número XXIII es una bella versificacion de un pensamiento escrito en prosa por este autor (Varela, 1887: 20).

Esto permite a Dieter Oelker (2003) afirmar que este informe es "fundamentalmente epigonal, apegado a las reglas, normas y formas consagradas y convencionales (...) [revelando] la incapacidad de la crítica de percibir e identificar lo nuevo en gestación. [Lo que] Se manifiesta en los panegíricos exagerados, preceptiva academicista, retórica y gramatical. No va más allá de la tradición" (156).

El informe, por otro lado, otorga legitimidad, al ser enunciado por un jurado competente, un escritor/intelectual, un historiador, un publicista periodista y crítico literario; Lastarria, Barros Arana y Blanco Cuartín. La institución se legitima al legitimar al jurado como miembros y agentes competentes y otorga valor de verdad a sus enunciados; valor normativo, legal, y valida el certamen como acto. 
Con respecto al jurado, éste mismo señala en el libro del certamen Varela:

Los infraescritos, al proceder de la manera que se expresa en este informe, no han perdido jamas de vista su propósito de ser justos e imparciales en la aplicación de su criterio literario. I favorecidos por la analogía de su espíritu i de sus principios en la materia, así como por la circunstancia de ignorar completamente quienes son los concurrentes, creen haber correspondido a la confianza con que los han honrado, tanto el iniciador del certámen como los escritores que con visible entusiasmo han venido a comprobar las dotes de su inteligencia i su amor al cultivo de las letras. Tal vez han sido severos en su crítica literaria; pero tal severidad se abona por la imparcialidad i tambien porque no han tenido voluntad de ofender o de desahuciar a los escritores, sino mas bien la de estimularlos con la verdad, apartándolos de errores que fácilmente pueden corregirse, según el juicio que se han formado (Varela, 1887: 42).

Finalmente, el discurso del informe legitima un canon a partir de una muestra, de un corpus que se estima representativo y permite distinguir a los "mejores".

\section{Los efectos o respuestas de la comunidad}

Entre los efectos, el que más nos interesa tiene que ver con la polémica que se suscita inmediatamente después del fallo, a través de la prensa. Esta controversia instala claramente la percepción de la existencia de dos grupos que se disputan el poder simbólico: los "viejos" y los "nuevos", o en otros términos: incumbentes y contendientes. El primer artículo, aparecido al día siguiente del fallo en La Libertad Electoral, señala que debido a "la buena voluntad y dedicación de ellos [los miembros del jurado], el certamen ha producido todos sus buenos resultados a favor de los que a él han concurrido y de desarrollo intelectual que el señor Varela quiere estimular"

Gran parte del éxito se debería, según el artículo, a la "universal aceptación, integridad y señalada competencia" de los integrantes del jurado y, un segundo factor, a que hayan participado "antiguos y distinguidos literatos". Incluso el autor llega a proponer que el sistema del certamen se tome como modelo en la elaboración de los textos de enseñanza.

${ }^{5}$ Oelker (2003: 144), citando el artículo "Nobles esfuerzos", en La Libertad Electoral, 16 de septiembre de 1887. 
Cuatro días después otra opinión en La Época: Gil Pérez (seudónimo De José Gregorio Ossa) afirma que difiere de los que piensan que "los premios se han hecho para estimular a los jóvenes y no a maduros escritores que suficientemente han demostrado ya de cuanto son capaces" (citado en Oelker, 2003: 144).

En ese mismo diario y en la misma fecha, aparece una nota firmada por "Uno que no ha concurrido a los certámenes" que dice: "los certámenes literarios del género y de la cantidad de los del señor Varela, eran y debían ser un estímulo para la juventud que desea trabajar y surgir y no un negocio para los jubilados de las letras". A lo anterior se suma Eduardo de la Barra (uno de los premiados, del grupo incumbente), quien responde con unas fábulas en La Libertad Electoral (16 de septiembre de 1887), defendiendo a los consagrados:

Fijar sexo y edad al arte, al cabo

Sólo puede ocurrírsele a algún pavo

Que, escaso de valía y de cacumen

Pide alevoso la exclusión del Numen (citado en Oelker, 2003: 144).

Nos encontramos, entonces, con la defensa de los "incumbentes" o actores que detentan el poder en el contexto inmediato, en respuesta a las críticas de los que defienden el lugar de los jóvenes en el espacio literario. Configurando dos grupos que difieren no sólo en edad sino en proyectos estéticos.

La segunda polémica se realiza a partir de Rubén Darío, aparece un elogio del canto épico ganador (de Jorge Huneeus Gana) y una inmediata respuesta crítica, que destaca los errores y fallos en el poema, realizada por Eduardo von Warner, luego, otra defensa esta vez hecha por Alfredo Irarrázaval Z ( La Época, 29 de oct. de 1887) .

Recordemos que Rubén Darío comparte el primer premio con un "canto épico" hecho a pedido, prácticamente. Se supone también, que compite atizado por el premio en dinero que ayudaría a su desmedrada situación económica. No obstante, se trata evidentemente de un gesto de instalación en el campo, y, esta instalación, será un acto público que colaborará para la publicación de Azul, el año siguiente, y que inicia la visibilidad del Modernismo.

Se trata de la oposición entre los modelos de "la vertiente ilustrada positivista" que porta una estética apegada a la norma y a la tradición" correspondiente a los

${ }^{6}$ Finalmente, en otro texto de Von Warner, se critica que se haya tomado como modelo los poemas de Bécquer para la poesía, pues el poeta no es fundador de una escuela y porque este modelo de "género sugestivo o insinuante" ofrece un marco reductor para la poesía. 
preceptos del neoclasicismo y romanticismo. Entre ellos se puede mencionar a Eduardo de la Barra, Guillermo Matta, Guillermo Blest Gana. Y, en el lado opuesto, los que formarán parte de la llamada "Bohemia dorada", formada por Darío, Narciso Tondreau, Manuel y Emilio Rodríguez Mendoza, Alberto Blest Bascuñán, Pedro Balmaceda Toro, jóvenes liberales, postrománticos y esteticistas; de acuerdo a la lectura de Bernardo Subercaseaux.

Finalmente, es importante agregar la figuración de la prensa, es a través de ella que se llama al concurso, se publica el fallo ${ }^{7}$ y se perciben sus efectos en las controversias y recepción crítica. Se trata del auge de la prensa y del inicio de su modernización, en los diarios y revistas participan los literatos emergentes, constituyéndose un espacio que favorecerá la formación de los escritores y al mismo tiempo configurará parte de la red que permitirá su circulación pública y el aumento del prestigio del escritor (Catalán, 1985), otorgando valor literario, y colaborando en su difusión e imagen pública. Dos diarios figuran especialmente: $L a$ Época, en torno al que se reúnen los jóvenes escritores, y $L a$ libertad electoral.

\section{CONCLUSIÓN}

El concurso funciona tal como funcionaría un enunciado como "yo los declaro marido y mujer", en las circunstancias de enunciación o poder, correspondientes. El acto literatura es reemplazado por el acto concurso, no es la literatura la que se instaura a sí misma como un hecho social-cultural, sino a través de una serie de prácticas, entre ellas la crítica, los concursos, las polémicas.

Por lo tanto el certamen instaura una literatura no en cuanto a textos, sino a textos legitimados institucionalmente, al declarar, por una parte, los requisitos del concurso y, luego, coronar a los ganadores. Se instaura una legalidad vigente y la existencia de los concurrentes a esa legalidad, por lo tanto, la existencia de contendientes en un espacio llamado campo.

El certamen Varela, como acto, sintetiza los componentes del campo literario, agentes, estrategias, hábitos, relaciones de poder y competencia por el poder simbólico, incluyendo las disputas entre proyectos literarios.

\footnotetext{
${ }^{7}$ Se realiza la publicación del informe del jurado en Los Debates, con fechas 13, 14 y 15 de septiembre, pero conservando los nombres de los participantes en secreto. Se publicaron tanto los nombres como el veredicto final el 16 de septiembre, siendo públicamente reconocidos los escritores en la fiesta del certamen que se realizó el 18 de septiembre del mismo año.
} 


\section{REFERENCIAS}

Aguilar, Hugo. 2004. La performatividad o la técnica de la construcción de la identidad, en Jornadas de Investigación de la Facultad de Ciencias Humanas. Universidad Nacional de Río Cuarto, Río Cuarto, Argentina. [En línea]. Disponible en http://www.unrc.edu.ar/publicar/borradores/Vol7/pdf/La\%20 performatividad $\% 20 \mathrm{o} \% 20 \mathrm{la} \% 20$ tecnica $\% 20 \mathrm{de} \% 20 \mathrm{la} \% 20$ construccion $\% 20$ de\%20la\%20subjetividad.pdf. [Consulta: 18/10/2008].

Austin, John Langshaw. 1996. Cómo hacer cosas con las palabras. Barcelona: Paidós.

Bourdieu, Pierre. 1990. "El campo literario. Prerrequisitos críticos y principios del método", Criterios 25-28, pp. 20-40.

Catalán, Gonzalo. 1985. "Antecedentes sobre la transformación del campo literario en Chile entre 1890 y 1920”. En José Joaquín Brünner y Gonzalo Catalán. Cinco estudios sobre cultura y sociedad. Santiago de Chile: FLACSO.

Lyotard, Jean Francois. 1994. La condición posmoderna. Madrid: Planeta Agostini.

Oelker, Dieter. 2003. "Certificación histórico-literaria del Certamen Varela". En Mario Rodríguez y Pedro Lastra (ed). Félix Martínez Bonati. Homenaje. Concepción: Editorial Universidad de Concepción, pp.137-158.

Promis, José. 1977. Testimonio y documentos de la literatura chilena (1842-1975). Santiago: Nascimiento.

Schechner, Richard. 2000. Performance. Teoría y prácticas interculturales. Buenos Aires: Libros del Rojas, Universidad de Buenos Aires.

Subercaseaux, Bernardo. 2000. Historia del libro en Chile (Alma y cuerpo). Santiago de Chile: Lom, $2^{\mathrm{a}}$ ed.

Varela Certamen. 1887. Obras premiadas y distinguidas. Tomo 1. Santiago de Chile: Imprenta Cervantes.

Williams, Raymond. 1980. Marxismo y literatura. Barcelona: Península. 